\title{
ONTWIKKELING EN PERSPEKTIEF IN DIE AFRIKAANSE POESIE
}

In die oorweging van my opdrag - om te praat oor ontwikkeling en perspektief in die Afrikaanse poësie - het ek my afgevra of, en in hoeverre dan, die terme „ontwikkeling" en "perspektief" in die verband met mekaar versoenbaar is. Op 'n bepaalde manier gesien dui dié woorde op twee benaderingswyses wat nogal skerp teenoor mekaar te staan kom. Rig ons ons op ontwikkeling, is die geskiedenis, die verloop in die tyd van deurslaggewende betekenis en sal ons in 'n hoë mate chronologies (of miskien anti-chronologies) te werk moet gaan, sal ons as 't ware saam met die tyd oor die hele terrein van ons poësie moet beweeg. Soek ons na perspektief, daarenteen, word die persoonlike instelling deurslaggewend, want nou staan ons stil en kan ons vanaf 'n bewus gekose, voordelige waarnemingspunt die landskap in oënskou neem, kan ons verskynsels en verhoudinge weergee soos hulle op ' $n$ bepaalde moment in ons gesigsveld te staan kom.

En tog kan die ontwikkelingslyn en die perspektieflyn mekaar ontmoet, en wel daar waar ons ons besin op dit wat eietyds is. Die ontwikkelingslyn moet uiteindelik by ons eie tyd uitkom, terwyl die soeker na perspektief as kind van sy tyd noodwendig sy waarnemingspos êrens in die hede sal moet oprig.

Dus: die nadruk moet val op die hedendaagse Afrikaanse poësie.

Maar hiermee duik 'n ander probleem op, want watter Afrikaanse poësie is hedendaags? Die van die moderne twintigste eeu? Die van na 1930? Die van na die Tweede Wêreldoorlog?

Miskien sal $u$ sê: die werk van die jong, opkomende kunstenaars. Maar dan moet $u$ onthou dat Van Wyk Louw en Elisabeth Eybers (wat dertigers is) en D. J. Opperman (wat 'n veertiger is) juis vandag in die Afrikaanse digkuns die toon aangee en nie die jong groepie beginners, byvoorbeeld, van wie daar 'n tyd gelede 'n bloemlesing onder die titel Stiebeuel verskyn het nie. Die jong kunstenaars gee by ons nie die toon aan nie, al is hulle soms die luidrugtigste en al ontvang hulle dikwels die meeste reklame.

Miskien verstaan $u$ onder hedendaagse poësie dit wat nuut 
en revolusionêr is. Goed. Maar nou moet $u$ weer onthou dat die sestigjarige Van Wyk Louw met sy jongste bundel, Tristia, 'n vernuwing bring wat in elke opsig stoutmoediger en belangriker en frisser is as dit wat die sestiger Breyten Breytenbach bring met sy bundel Die ysterkoei moet sweet. Bowendien, Van Wyk Louw se nuutheid is 'n nuutheid waartoe hy gegroei het uit eie krag; Breyten Breytenbach se nuutheid is in hoë mate ' $n$ modeverskynsel en daarom in essensiële sin nie so danig nuut nie.

Alles in aanmerking genome sal ek my opdrag miskien dus die beste kan uitvoer as ek nie die aksent op figure laat val nie maar eerder op bepaalde neigings, tendense wat gedurende die afgelope tien, vyftien jaar al duideliker voelbaar word in die Afrikaanse digkuns. En hierdie neigings sal ek die duidelikste kan laat spreek as ek telkens die nuwe, die eksperimentele, die kontroversiële teenoor die ouere en die geaksepteerde stel. So kan die begrippe ontwikkeling en perspektief beide enigsins tot hulle reg kom. Die nadeel is dan net dat ek nie noodwendig die beste van ons tyd aan u sal kan voorhou nie. Dit wat uiterlik 'n nuwe of revolusionêre voorkoms het, is lank nie altyd goed of belangrik of selfs wesenlik nuut nie.

Om goed te begryp wat die afgelope tien, vyftien jaar in die Afrikaanse poësie aan die gang is, sal ons vir 'n oomblik die oog vlugtig moet laat gaan oor die Afrikaanse poësie van hierdie eeu. Ek hoef hierdie gehoor nouliks daaraan te herinner dat daar in die tyd duidelik vyf, ses generasies te onderskei is: die sg. Driemanskap (Totius, Celliers en Leipoldt); dan die Twintigers met Toon van den Heever as sterkste figuur; die Dertigers met N. P. van Wyk Louw as woordvoerder en gangmaker; die Veertigers met D. J. Opperman aan die spits; die Vyftigers met Peter Blum en die Sestigers met Breyten Breytenbach as digter wat die meeste aandag en publisiteit ontvang.

Hierdie lys is natuurlik lank nie volledig nie, maar dit hoef ook nie. Vir ons doel is dit belangriker om daarop te let dat daar bepaalde uiterlike faktore opgenoem kan word wat in die loop van hierdie sestig jaar 'n vormende rol in die digkuns gespeel het: die oorloë, byvoorbeeld; die trek na die stede en die ekonomiese en godsdienstige spanninge wat dit vir die Boere-Afrikaner meegebring het; die politieke emansipasie van die Afrikaner en die erkenning van sy taal as me- 
dium in die kerk, die skool en die staat; die rassesituasie in ons land en Suid-Afrika se posisie in die wêreldpolitiek; die Afrikaner se steeds wyer wordende belangstelling in die kunste, met name die skilderkuns en die literatuur van WesEuropa. Die Afrikaanse poësie is dus nie 'n fraaiigheidjie aan die buitekant van ons nasionale lewe nie. Dit groei saam met die volk, en tot op groot hoogte lê daarin uitgedruk die stryd en lyding van die Afrikaner, sy nasionale aspirasies, sy groei tot volwassenheid - plek-plek miskien ook sy verraad.

In die verband is dit nou insiggewend om te let op ' $n$ ontwikkeling wat die afgelope klompie jare steeds duideliker merkbaar word. Tot en met die Tweede Wêreldoorlog is die Afrikaanse vers uitsluitend beoefen deur digters wat tot op groot hoogte binne die Afrikaanse tradisie en strewe gestaan het: Totius, Celliers, Visser, Toon van den Heever, Van Wyk Louw, Opperman - noem maar op. Leipoldt was van Duitse afkoms; hy is 'n kosmopoliet genoem, en hy was dit. Tog het hy in sy oorlogspoësie felle uitdrukking gegee aan die lyding en onreg van die oorlog, en so het van sy verse geliefde „volkspoësie" geword.

Sedert 1940 het die nie-Afrikaner ook stem gekry in ons poësie. Ek dink hier aan die werk van die Kleurlinge Petersen, Philander en Small; aan die werk van „vreemdelinge" soos Olga Kirsch en Peter Blum. Hieroor kan 'n mens jou verheug; dis ' $n$ verblydende aanduiding van die uitdyende gebied van ons taalinvloed. Maar dit het ook komplikasies meegebring. Die Afrikaanse literatuur was nie langer uitsluitend die literatuur van die Afrikaner nie. Die taal was nou nie meer "gansch het volk" nie. Tot en met die Tweede Wêreldoorlog het die Afrikaanse digter hom natuurlik meermale geopenbaar as die opstandige, die afwykende en afwysende enkeling wat dit in meer as een opsig buite die grense van die aartsvaderlike wêreld gewaag het: Marais, Toon van den Heever, Van Wyk Louw, byvoorbeeld. Daar was kritiek en verset, maar dit was 'n "lojale verset" wat hom selde of ooit teen die identiteit van die Afrikaner gerig het. In die afgelope jaar of tien is daar egter hier en daar ' $n$ ander gees te bespeur. Miskien hang dit saam met die politieke druk wat van buite teen ons land volgehou word; miskien is dit 'n verbygaande mode. Ek weet nie. Maar feit bly dat daar vandag, ook via die Afrikaanse literatuur, dikwels in die taal van 'n vyandige pers, aanvalle geloods word op die Afrikaner en dat daar tans 
meer as een stuk literatuur verskyn wat teenoor die Afrikaner en sy bestaanstryd koud en afwysend staan, indien nie vyandig nie. En hierdie houding word nie slegs by enkele „vreemdelinge" aangetref nie. Nog onlangs het iemand soos Breyten Breytenbach in die pers verklaar dat hy skaam is om 'n Afrikaner te wees, 'n ander skrywer dat hy skaam is om 'n blanke te wees. Meer as een Afrikaanse outeur het al gedreig om in Engels te skrywe en om permanent in die buiteland te gaan woon.

Nou wil ek nie beweer dat die „vreemdeling” noodwendig antagonisties teenoor die Afrikaner staan nie; ook nie dat daar langs dié weg nie ' $n$ belangrike bydrae tot die Afrikaanse poësie te lewer is nie; ek wil alleen maar sê dat ons, ook in die letterkunde, besig is om die prys van ekspansie en inklusiviteit te betaal. Daar is ' $n$ koue wind aan die opsteek in ons literatuur. Ons sal byvoorbeeld merk dat dinge wat vir die Afrikaner hoë waarde het, toenemend behandel gaan word op ' $n$ siniese of lughartige of respeklose wyse wat dikwels aan ontwyding grens.

Uit so 'n kritiese gesindheid is natuurlik literatuur te maak, mits die skrywer kan uitstyg bo sy eie beperktheid en knorrigheid. 'n Voorbeeld hiervan is die volgende sonnet van Peter blum waarin ' $n$ Kaapse Kleurling spottend aan die woord kom na aanleiding van monumente en standbeelde in ons land. Daar sal natuurlik baie Afrikaners wees wat die Voortrekkermonument log en esteties onaantreklik vind, maar wat dit daarom nog nie bloot 'n voorwerp van satire sal maak nie, en wat dus in houding sal verskil van Blum en sy „Kaapse kjend". Wat nie wegneem dat ons hier 'n sonnet het wat in sy nonchalante onverskilligheid een van die beste, vindingrykste, ja, selfs vermaaklikste spotgedigte is in ons taal:

\section{OOR MONNEMENTE GEPRAAT}

Wat spog jul so met julle monnement?

Hy's groot ma' lielak, en hy staan so kaal da' op sy koppie. Wie't vir hom betaal al daai graniet en marmer en sement?

O ja, hy's groter as ' $n$ sirkustent ma' waa's die pêd, die mooi nooi innie saal? die lekka ,clowns', die leeus in hul kraal? Nei, daa's g'n spôts nie vir jou Kaapse kjend! 
Hier het ons stetjoes, elkeen soos ' $n$ mens: ou Afduim-Murray, Hofmeyr met sy pens;

Hier's Jan van Riebeeck, bakgat aangetrek

in sy plus-fours; Cecil Rhodes wat jou wys $w a^{\prime}$ die reisiesbaan lê; en vorie Paalmint-hys ou Mies Victôria met ha' klein spanspek.

U merk dit: Blum staan oop en vry; hy het geen bybedoelings nie, soek ook nie sy eiebelang nie. Daarom dat die gedig nooit haatlik word nie, behalwe miskien in die derde reël: „Wie't vir hom betaal". Hier word die satire krenterig. Ook merk $u$ dat die digter na alle kante toe spot. Hy raak die Afrikaanssprekende maar ook die Engelssprekende, die Transvaler maar ook die Kapenaar. Hy spot nie nét, of selfs in hoofsaak met die werklike waardes nie; hy spot met die swaarwigtigheid, die vertoon, selfs met die deftige poësie. Dis byvoorbeeld nie toevallig nie dat hy hier van die waardige sonnetvorm gebruik maak nie. Dit is hierdie oopheid, vindingrykheid, speelsheid wat die implisiete kritiek aanvaarbaar maak en die gedig tot kuns verhef.

Totaal anders is die toon meermale in die poësie van Adam Small, wie se werk in hoë mate geïnspireer word deur 'n gevoel van politieke frustrasie. Die gedig wat ek straks aan u gaan voorlees, is gerig teen die dominee wat dan in weelde sou swelg en weinig ervaar van die eenvoudige leefwyse van byvoorbeeld Johannes die Doper. Ons het natuurlik al by A. G. Visser spotgedigte gehad op die predikant:

Kom sê my die beduidenis

- ek moet my so verwonder -;

Langdradig op die preekstoel is

So kort van draad daaronder.

Maar by Small verdwyn die goedigheid, die „milk of human kindness", die gevatte geestigheid, en die resultaat is 'n suur, humorlose vers wat wil-wil in skellery ontaard:

\title{
DOEMANIE
}

\author{
' $n$ Proefiet van Jesus djy?? \\ 'n proefiet? \\ djy moet djou palys-hys \\ djy moet djou aeroplane-motorkar
}




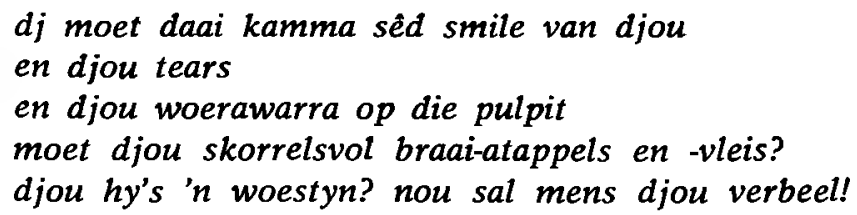

en hoe lyk dit met djou kale pote vi' daai streamline ding en hoe lyk dit moet djou toega vi' die vel van 'n kameel hoe lyk dit met daai skorrelsvol vi' sprinkane en wille

Hierdie spottende of aggressiewe toon by enkele jongeres word nie altyd geïnspireer deur 'n verset teen die Afrikaner nie. Plek-plek sluit dit aan by 'n breër Europese gees wat op byna kwajongagtige wyse probeer afreken met oorgelewerde waardes. Dit sien ons veral by iemand soos Breytenbach. Op talle maniere kom dit tot openbaring: 'n strewe om te debunk. Daarby dat hy byvoorbeeld, net nadat hy die woord "hart" in 'n gedig gebruik het, hierdie betekenis tussen hakies byvoeg:

(ek het nooit gedink dat ek

oor hart sou uitwei nie, die klotsel bloed

in pypies en kraakbeen).

Maar laat ons ter illustrasie slegs die behandeling van een motief in oënskou neem: die natuur.

By Leipoldt kry ons 'n juigende opgaan in die natuur wat vir hom 'n troos is, 'n ,towerpaljas": "Somer en son en saffier vir my". By Toon van den Heever is die natuur nie meer so ongerep nie; die skoonheid van die Hoëveld „waar kuddes waaigras huppel oor die veld" word as 't ware aangetas deur die myn en die leed van die teringlyer. By die Dertigers kry ons nog die natuur, byvoorbeeld in Van Wyk Louw se pragtige „Gebede by die jaargetye in die Boland". Maar nou is die natuur nie langer 'n motief nie; dit word hoe langer hoe meer materiaal wat die digter in sy skeppingsproses gebruik en verbruik. Vgl. bv. so 'n reël:

Net nog die ou leed waai deur die skemering.

Dit gaan hier om die verbeelding van die menslike "leed" en nie om die uitbeelding van die wind in die skemering nie. Nog duideliker merk ons die ontwikkeling by Opperman. 
Nêrens leef ons land met sy diere en plante, sy berge en vlaktes so sterk as in sy poësie nie. Maar nooit kry ons by hom, soos by Leipoldt, 'n besinging van die skoonheid om die skoonheid nie. Slegs binne die gedig kry die natuurwerklikheid sy sin en waarde. Dit gaan nie om die "mot" nie maar om die "mot in barnsteen", nie om die "wit duif" of "groen blaar" nie, maar om 'n skepping wat stol tot "beelde agter glas".

Ook in die jare vyftig en sestig sal die natuur terugkeer, maar dan dikwels opsetlik ontluister, ontwy, sodat ons byna van 'n bewuste ontromantisering kan praat, soos by Breytenbach:

die nag buite is swart, nie blou nie, nie groen nie en nie poëties nie...

'n wekker hakkel op my tafel, met die lig sal dit my [wakker vloek,

want ek moet vroeg uit, melk koop vir brekfis

plante op die kas se blomme is soos naels afskot die mure verdroogde binnevel van 'n siek vierkantige krap kewers kuier oorvreet op teen klotsende waterpype daar is weinig kleur, swart en wit, dit skok nie dis die nag van my wakkerword.

Hier kan geen sprake wees van 'n skoonheidstroos nie; eerder is dit die uitdrukking van 'n eksistensiële walging en malaise.

Natuurlik het vorige geslagte in die Afrikaanse digkuns ook meermale die neerdrukkende aspekte van die bestaan en die natuur raakgesien. Opperman se reis gaan byvoorbeeld ook deur die "grysland" van die stad, deur die "gramadoelas" van die land. Hy het ook die miskruiers en die maaiers en die kakkerlakke op sy weg ontmoet, maar hy voer hulle die gedig in soos Noag sy diere in die ark. Soos Jorik, aanvaar hy hierdie reis in opdrag van die "Een wat heers", en hoe dieper hy hom inlaat met die grou wêreld van die tyd, hoe onverbiddeliker voel hy hom kontraktueel gebind om in die tyd die tydlose te ontdek, om die engel uit die klip te verlos, om die verganklike skepping in essensie en onverganklik te bewaar in die "ark van genade" wat die gedig is. Vir 'n digter soos Breytenbach en sy geesgenote is hierdie verlossende moontlikheid blykbaar uitgesluit; hy is reddeloos uitgelewer aan die banale werklikheid van uur en feit, die klein heelal van kamer, van bed, van die eie liggaamlikheid. 


\section{Die godig:}

Tot dusver het ek slegs enkele historiese lyne getrek uiterlike aanduidings gegee en in die proses eintlik om die gedig heen getas. Ek wil nader aan die kern beweeg deur agtereenvolgens die aksent op drie aspekte van die poësie te laat val: die woord, die beeld, die opvatting aangaande die aard van die gedig.

\section{Die woord:}

Blaai ons deur die ouer Afrikaanse digbundels, sal ons 'n sterk voorkeur opmerk vir woorde wat reeds 'n sekere poëtiese klank en geldigheid besit. „My vuurtjie en ek is op wag", „O koud is die windjie en skraal”. Sodra die digter egter met ' $n$ ruwer werklikheid te make $k r y$, is hy ook verplig om die ruwer woord toe te laat, soos Leipoldt byvoorbeeld met sy "kinkhoes en tering" en Totius in sy Trekkerwee (1915) waar die agterbuurt van die grootstad só gesien word:
Die voorpos van die armes woon in Blikkies-dorp se kronkel-sink wat ver soos bottelstukke blink. Hut lewe van 'n hongerloon in huisies aanmekaar gepas en jaartjies vol van steenkool-as.

Geen wonder nie dat dit juis Opperman moet wees, die veertiger, wat later so bewonderend oor hierdie gedig van Totius sou skryf, want dit was juis Opperman en sy geslag wat die hele taal in prinsipe oopgestel het vir die poësie, wat selfs die onmooie, onpoëtiese, banale woord in die poësie toegelaat het. Luister maar na hierdie beskrywing van 'n Kaapse mark soos Opperman se Jorik dit sien:

'n Ou Mark: langs kalkstrepe op die Plein staan groen vragmotors, ongeskeerde mans uit die Pêrel, Wellington en Drakenstein, Verdruk-my-Nie en van Kleinwolwedans;

Bruinmense met tamaties en kropslaai, en Grieke koop geelwortels en radyse! Wie het die appels in papier gedraai? Hier lê 'n springbok, daar 'n paar patryse. 
Hy hoor die karretjie met groot geraas

van wiele en van perdepote om die hoek, en die Maleier sy vals beueltjie blaas

en skree: "Kabeljou, galjoen en snoek!"

Met die manbaarwording van ons poësie was dit 'n volkome natuurlike ontwikkeling.

Hierdie ekspansie van die poëtiese woordeskat word verder gevoer in die jare vyftig. Soos ons reeds gemerk het by Blum en Small, word ook nou die onafrikaanse, afwykende woord, die patois tot poësie gedwing. 'n Uiterste konsekwensie van dié ontwikkeling word bereik waar die woord 'n irrasionele grens begin nader, soos byvoorbeeld in die merkwaardige gedig "Man wat mal word", waar Blum die woord opsetlik vermink in 'n poging om die aftakeling van die rede onmiddellik te versigbaar:

Onbepeilboor die dag, maar bewoespyn dààr dat al-lis beslote is en slags èk oop vir enige skerf nael, skermloos teen die oog wat drin die werwel noulet, fynynig vaam

tort in die klier... ens.

Neem in die eerste reël die sleutelwoorde "onbepeilboor" en „bewoespyn”. Wat beteken dit? Op die oog af lyk „onbepeilboor" op 'n soort kontaminasie van "onpeilbaar" en „onbepaalbaar" - „onbepeilboor die dag". Die dag is onbepaalbaar, onpeilbaar, onbegryplik vir die kranke brein, en tog boor die lig in in die bewussyn (,bewoespyn"), bring dit in daardie woeste chaos nie lig of begrip nie, maar pyn. Hier skemer nog flitse redelikheid deur, maar dit wil voorkom of Breytenbach miskien nog 'n stap verder gaan in die volgende fragment waar die labiele balans tussen die rasionele en die irrasionele prysgegee word. Hier word 'n swaardgeveg opgeroep met 'n reeks woorde wat geen rasionele inhoud meer het nie, slegs klanknabootsende effek besit:

En garde!

Kleng jaa tjeng tjang tjeng kleng Ai joei tsji tsjan bik sjoeing tjôrr

Fuut tjeng wam kieng oo sssip

Ha klang klang klang tjing ssip

Hû merde tjong fuut kleng jaa 
Sjoeing klub kieng konk hoender dirr

Rrruf tjang tjenk wam aaa ssip

Kak tjeng klieks zem zem ung ha

Touché

Aaaaaaaaaaaaaaaaaaaa

(ek voel sy swaard soos 'n graad in my gorrel).

Dis natuurlik 'n klein kunsie om so iets belaglik te maak. Ek glo nie dat ons hier 'n besonder vrugbare eksperiment het nie, en hiermee is seker so ongeveer ' $n$ eindpunt bereik, maar as iets unieks in Afrikaans bly dit nietemin interessant, toon dit waarheen die eksperiment met die woord kán loop.

\section{Die beeld:}

Ook op die gebied van die beeld (die metafoor en die vergelyking) sal daar in die Afrikaanse letterkunde oor die loop van jare interessante eksperimente en innovasies merkbaar word. Naas die rustige, eksplisiete gelykstellings van Totius, byvoorbeeld "O wilgerboom ... beeld van my skuld", doen die beelde van meer as een veertiger snel aan, kripties, sodat die leser groter verbeeldingspronge moet mak. Maar hoe snel die metaforiese werking ook al was, altyd nog het die rasionele of visuele band tussen die twee lede van die vergelyking behoue gebly. As Opperman byvoorbeeld praat van: „die beitelpunt van die rivier", dan is dit duidelik dat dit gaan om die erosie-effek van die stroom wat sy walle wegvreet. ' $n$ Mens sou tientalle van hierdie merkwaardige metafore uit hierdie digter se werk kan haal, byvoorbeeld waar die skuld opgeroep word van 'n geslag wat met elektriese maste en myntorings die natuur van die land geskend het:

Ons het die geeste van ou ooms verraai waar ysterstruike aangroei in hul land en warrelwinde uit mynhope draai.

Of waar die brose liggaam van die mens met sy fragiele beenstruktuur gesien word as:

strooisie vlees en been.

Of waar die nuuskierige astronoom met sy teleskoop op onvergeetlike wyse geteken word as:

„Die volmaakte dier wat snuiwe aan die sterre met 'n lens". 
Of waar die lughartige en onverskillige Dabor vir Jorik probeer troos met die woorde:

Ons maak maar almal 'n geraamte groot.

Maar soos gesê, altyd nog kan ons in hierdie snel metafore rasioneel of visueel die kloutjie by die oor kry.

By 'n digteres soos Ingrid Jonker, byvoorbeeld, kry die beeld egter meermale 'n surrealistiese trek, raak die skakel tussen beeld en toepassing verbreek, sodat daar ook 'n element van gewildheid sigbaar word, soos byvoorbeeld die volgende wat waarskynlik van Lorca af via Uys Krige in die Afrikaanse poësie ingekom het:

$$
\begin{aligned}
& \text { Ek weet tog } \\
& \text { jou mond is ' } n \text { nessie } \\
& \text { vol voëltjies. }
\end{aligned}
$$

Of: Jou lag is 'n oopgebreekte granaat.

Al wat ons kan sê, is dat hierdie metafore iets van die helderte en kleurrykheid van die lag (sang?) suggereer. Meer nie.

By Breytenbach is die beeldvorming ' $n$ veel bewuster proses as by Ingrid Jonker. En in sy beeld sal ons ook tekens vind van die opsetlike ontluistering wat ek vroeër genoem het, vgl. byvoorbeeld:

Die maaltyd:

hier op my bord het ek die reste van my drome; blou niere, pers vesels afgetakel

' $n$ babbelende skedel die somber geheime mond die groen vleis van plante 3 ö̈ wit en rond

aangename eetlus!

Dit wil voorkom of die digter nie op soek is na ooreenkomste nie; hoogstens probeer hy met die vergelyking of metafoor 'n bepaalde stemming wek, soos in die volgende gedig waar die baaier iets van 'n loutere liggaamlike genot wil uitdruk as hy die helende effek van son en seewater ondergaan; dis asof hy 'n genesende natuuroperasie ondergaan:

plastiese snykunde

die son skalpeer met sy messe aan my lyf 
die seewater woel sy verbande om my wonde die vars lug se strale brand die gewasse van my longe

sodat die bene van my ou karkas vermurwe en ek deursigtig wit is

fliepflap in die water

spoel en sug

' $n$ opgeblase pienk orgaan sonder vel

maar die dokter was my genadig:

agter die ritsluiter van my maag bêre ek visse en klippe

skulpsakke vroetel in die seewier van my hare

my neus is ' $n$ snorkel om bo watervel te kan snuffel my een voet is ' $n$ periskoop

en my ander' $n$ derde hand

en een oor is diep om onder water mee te luister

my hart 'n skuifelende seekat

\section{Veranderende opvatting aangaande die aard van die gedig:}

Die afgelope jare het ook meer as een gedig opgelewer wat daarop dui dat daar 'n veranderende opvatting aangaande die aard van die gedig aan die ontwikkel is. Hierop kan ek hoegenaamd nie uitvoerig ingaan nie; ek wil volstaan met twee vlugtige aanduidings.

By die veertigers, meer bepaald by Opperman, maar ook by Ernst van Heerden, het ons 'n sterk neiging opgemerk om byvoorbeeld met behulp van die literêre verwysing die gedig met 'n maksimale inhoud te laai. Die tradisie agter die vers het groter en ryker geword, en die uitkoms was die gekompliseerde, kriptiese laaggedig wat hom op verskillende vlakke laat lees. So 'n gedig is die volgende kwatryn uit die reeks Diereriem van Opperman - nie een van Opperman se beste vierreëlige gedigte nie, maar vir ons doel insiggewend genoeg:

\section{Leeu}

Hy gloei voor my uit die braambos en vlam op vlam skud $H y$ Sy maanhaar los, die koninklike vuur van die heelal wat my van bloed en vlees verlos. 
Met die eerste deurlees is hierdie gedig nors, geslote en duister. Die digter gee hier slegs enkele kriptiese aanduidings en laat dit aan die leser oor om die patroon in sy gees te voltooi. En om die patroon te voltooi vereis heelwat agtergrondkennis en inspanning. Ons moet byvoorbeeld iets weet van die twaalf gestaltes van die diereriem: die bul, die tweelinge, die krap, die leeu, die maagd, ens. Verder moet ons iets weet van die astrologiese bygeloof wat wil dat die lotgevalle van die enkeling bepaal word deur die sterrebeeld waaronder hy gebore word. In hierdie geval is dit die leeu wat hom met sy vorstelike voorkoms laat geld, herskeppend ingryp in die lewe van die mens om hom van bloed en vlees te verlos. Hoe lyk hierdie leeu? Met sy skuddende maanhaar word hy die vuurgloed in die bos, die braambos. En hiermee word dadelik assosiatief in herinnering gebring die roeping van Moses toe hy God in die brandende braambos ontmoet het. Die leeu van die diereriem en die bygeloof word hier dus die Leeu van die heelal, God (let op die hoofletter van "Hy” en "Sy" in v. 2) wat in 'n wonderlike verskyning vir Moses roep tot ' $n$ taak en so kragdadig ingryp in die lewe van ' $n$ mens. Maar ons weet dat Moses onwillig was, ook omdat hy gehakkel het, gebind was deur liggaamlike beperkings; maar ons weet ook dat God sy besware uit die weg geruim het, deur hom haas bomenslike mag te gee. So kon Moses uitstyg bo die beperkinge van die liggaam en 'n instrument word in die verlossing van sy volk. Onder die dwang van hierdie magtige Leeu-ster word die brose mens dus die geroepene, die profeet wat die verlossende daad kan verrig. Hiermee kom die verlossingsmotief na vore wat ons so dikwels in Opperman se poësie ontmoet, en teen die agtergrond van Moses se roeping en taak sou 'n mens die digter kan sien as die eertydse onmagtige stamelaar wat deur God voortgedryf word, uit bo die beperkinge van bloed en vlees geroep word om die verlossende woord in die skepping te spreek.

In die jare vyftig kom daar 'n ligtere, oper, deursigtiger volkspoësie in swang, 'n poësie wat bekoor deur sy speelsheid eerder as deur sy kriptiese geladenheid. Die soort gedig sal ons byvoorbeeld vind in Van Wyk Louw se "Klipwerk"; De Vries se Proegoed en Boerneef se Krokos. Hierdie verse is ligter, skynbaar minder ernstig, hoewel hulle nie altyd so onskuldig is as wat hulle lyk nie en dikwels 'n ondertoon 
van tragiek of pyn laat hoor, soos in die volgende voorbeeld van Boerneef waar dit gaan oor die ellende van die droogte:

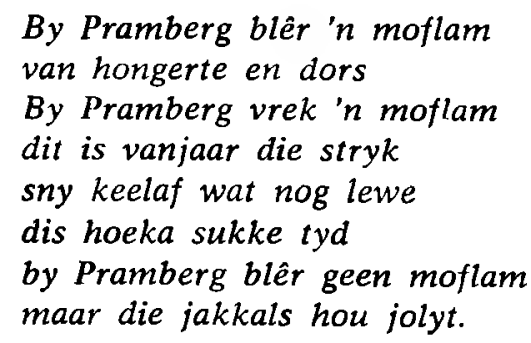

Hierdie gedig is in die verwesenliking van wat hy beoog nie sonder verdienste nie. Die naam "pramberg" is nie toevallig gekies nie; dit intensiveer byvoorbeeld deur kontraswerking die harde beeld wat hier van die natuur gegee word. Die natuur is hier nie langer die groot voedingsmoeder nie. Dit is verder opvallend hoe die digter met die herhaling 'n stygende nood suggereer, maar dit is ook duidelik dat ons hier 'n ander soort taalaanwending het, oper, primitiewer byna. Die tegniese vaardigheid en die intellektuele beheersing van die wêreld soos ons dit by Opperman teengekom het, moet ons hier nie soek nie.

Maar daar is ' $n$ ander neiging wat nog duideliker wys op 'n veranderde opvatting ten opsigte van die aard van die gedig.

Tot en met die jare vyftig was daar by ons sterkste digters, selfs in hulle mees persoonlike gedigte, 'n duidelike strewe merkbaar om weg te kom van die belydende „ek”, om persoonlike belewenisse te objektiveer. So maak Elisabeth Eybers haar portrette en skep Van Wyk Louw en Opperman hulle groot gestaltes. En selfs waar nie gestaltes geskep is nie, het persoonlike stemminge vorm en duursaamheid en universele betekenis gekry binne die struktuur van die vers. Die digter was nie die belyer nie maar die vakman wat 'n gedig bou in taal. Vandaar dat meer as een gedig in dié tyd gehandel het oor die probleem van die digterskap. So het die gedig 'n eie identiteit en status gekry. Die digter met sy eie gevoelens en drifte is weggeobjektiveer in 'n taalkonstruksie wat sy eie sê kon sê.

Hierteenoor doen meer as een gedig van Blum, Jonker, Small en Breytenbach ekkerig aan. Selde of ooit word die leser toegelaat om die skrywer te vergeet. Dit is dan ook simptomaties van ons tyd dat skrywers en digters so graag 
hulle menings in korrespondensiekolomme van koerante uitspreek. Die skrywer word prater, kletser wat uitflap. Ook in die gedig wil hy hom teen elke prys opdring aan die leser, wil hy met voorwoorde en nawoorde en verduidelikings die gesprek buite die kunswerk voortsit. By Breytenbach neem dit die vorm aan van 'n byna sieklike belangstelling in en vertoning van sy eie anatomie: sy kop, sy oë, sy neus, sy baard, sy karkas, sy derms, sy kieliebak. Sy heel eerste gedig word opgedra aan B. Breytenbach en begin so:

Dames en Here, vergun my om u voor te stel aan Breyten

die maer man met die groen trui; hy is vroom

[Breytenbach, en stut en hamer sy langwerpige kop om vir u ' $n$ gedig te fabriseer...

Elders laat hy hom só uit:

ek laat niemand op my kop sit nie kophou breyten breytenbach.

Ons het hiervan natuurlik vroeër ook iets gehad in Afrikaans. Die dertigers was self aanvanklik nie heeltemal vry te spreek van 'n sekere narcissisme nie: W. E. G. Louw het hom meermale poëties besig gehou met sy bleek hande en sy skraal heupe. Die verskil is net dat die beeld van die self tans sterk onromanties voorkom, vol misnoeë en walging. By W. E. G. Louw was daar natuurlik ook iets van die selfveragting, die verlore seunskap. Maar dit het basies 'n romantiese instelling gebly: die „vodde en die vuil" van die verlore seun kon met 'n towerslag vir die konings- of profetemantel ingeruil word. By Breytenbach gaan die walging dieper. Dit word 'n soort masochisme, 'n bewuste selfontluistering; dis 'n geskonde Breyten Breytenbach wat homself in sy gedig vertoon. Die vraag is net of dit nie ook maar weer iets van 'n pose is nie. Word die romantiek nie hier by die agterdeur ingesmokkel nie? Het ons nie hier 'n soort omgedopte selfbejammering nie? Hoe dit sy, met die opdring van die „ek" aan die leser loop die gedig as afsonderlike struktuur gevaar om aangetas te word. Die digter kán natuurlik 'n plek vind binne die gedig, maar dan slegs as vertroude ingewyde wat volkome opgaan, homself verloor in die wêreld van die gedig. Breytenbach bly, dikwels met naam en al, in meer as een gedig aanwesig. Dis asof hy die hele tyd besig bly met die 
gedig, voor die oë van die leser, en met behoud van sy identiteit, die gedig manipuleer.

'n Mens sou verskillende verklarings vir dié ontwikkeling kan vind. Ons sal byvoorbeeld kan sê dat met die geloof, hoop en liefde onder verdenking daar vir die moderne mens slegs die liggaam oorgebly het, die eksistensie waarvan die gedig deel moet vorm as hy nog vir die moderne digter (en leser?) iets wil beteken. Daarom dat Breytenbach aan die slot van een van sy gedigte dít binne die gedig as deel van die gedig kan skryf:

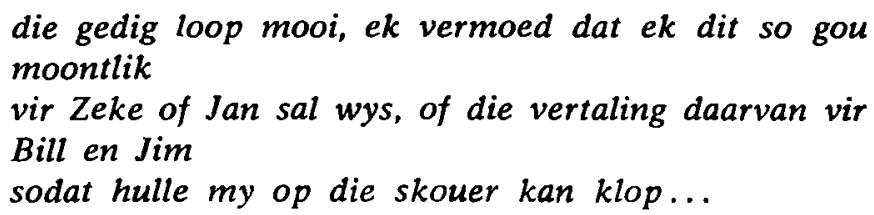

Dit is amper asof hy hom met opset wil handhaaf in die gedig, asof hy hom telkens wil losruk uit die ban van die woorde met dié waarskuwing aan homself: Oppas! Laat ek my perspektief bewaar, my eie identiteit wat per slot van rekening minstens net so belangrik is as die gedig.

Van Wyk Louw sou nog kon sê:

O Woord, geslote kamer vir die skoonheid klaar gaan oop vir my dat ek my in jou red met hierdie vrag van aardse sekerheid en pyn.

'n Digter soos Breytenbach sal dit nie langer kan skryf nie. Nie alleen het die ,aardse sekerheid" blykbaar verdwyn nie, maar die woord is geen "geslote kamer" meer nie, die gedig gevolglik geen toevlugsoord. Die geslote, afgeronde, heel struktuur van weleer sal by hom plekmaak vir die „stukkende gedig" wat geen beskutting meer kan bied nie. Maar waar geen verlede en geen toekoms is nie, is daar ook niks orn gebêre te word nie. Wat oorbly is die selfbeklag van die oomblik, wat tog nie sonder ontroerende patos is nie:

om 'n gedig te kan skryf 11-uur in die môre in die winter oor niks, behalwe die koue wat buite sigbaar is en die behoefte in die derms en die gebrek aan blomme en die droë ooglede, niks van agter en niks van voor net hierdie bepaalde tydstip wat net is omdat dit nou is. 
Lê hierteenoor 'n gedig soos Die beiteltjie van Van Wyk Louw. Waar Breytenbach die mens en sy triestigheid as vertrekpunt neem, daar is die taal en sy onbeperkte moontlikhede vir Van Wyk Louw die kiem van die gedig. Waar Breytenbach in sy miskenning van die gedig as gedig noodwendig in die moeras van sentimente en emosies moet bly steek, daar sal Van Wyk Louw, die „verbete formalis”, onder geleide van woord, beeld en ritme tot heldere klaarheid kom. Met die klinkende beiteltjie van die woord begin hy 'n onopsetlike spel, maar dis 'n spel wat groot gevolge kan hê, mits daar reg gespeel word.

Om aan te toon hoe die taal hier aan die bod kom kies ek 'n kort gedig uit Van Wyk Louw se jongste bundel, Tristia. Ons sal in hierdie gedig ou-ou poëtiese motiewe terugvind soos die afskeid van die geliefde, die eensame agterbly, die besef dat die wêreld daarbuite nie verander nie, behalwe dat alles met die afskeid net kouer en triestiger geword het.

Ons het hier dus ook die mens met sy verlangens en weemoed terug. Maar hoe word dit aangebied? Nie deur middel van direkte mededeling nie maar deur middel van die musikale ontginning van die taal, die herhaling. Let maar op hoe die wind en die winterse leegheid ongemerk die slotstrofe vul:
$J y$ 't weggegaan en jy bewoon
'n silwer herberg in die sneeu jou vensters kyk nog elke nag met drie blink oë na die plein
die plein is boom en wind en boom en wind en wind en wintermiddag voer daar iemand die meeue krummels teen die wind.

In poësie soos dié waar die taal en sy moontlikhede self die energiebron word van die gedig, waar betekenis as ' $t$ ware uit woord en ritme gepers word, kan die digter met sy eie ek bekostig om op die agtergrond te tree, want hier het ons met 'n "heel", volwaardige gedig te make wat sy eie sê kan sê.

Ek sal gewillig wees om 'n hele paar "stukkende gedigte" in ruil te gee vir 'n fyn konstruksie soos dié.

Pretoria.

A. P. Grové. 